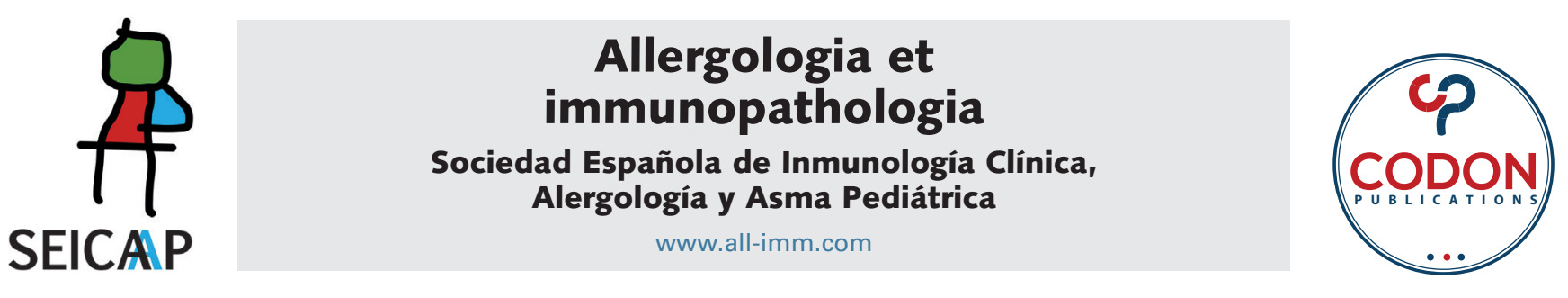

\title{
Investigating the association between allergic diseases and COVID-19 in 400 Iranian patients
}

\author{
Amirhossein Darabia , Mohammadrezad Dehghanfard ${ }^{\mathrm{b}}$, Sara Jozanc, Rahim Tahmasebia, \\ Ali Movahed d, Marjan Zamanic, Shokrollah Farrokhic*
}

\begin{abstract}
${ }^{a}$ Department of Epidemiology, The Persian Gulf Tropical Medicine Research Center, The Persian Gulf Biomedical Research Institute, Bushehr University of Medical Sciences, Bushehr, Iran

${ }^{b}$ Department of Orthopedics, Faculty of Medicine, Bushehr University of Medical Sciences, Bushehr, Iran

'Department of Immunology and Allergy, The Persian Gulf Tropical Medicine Research Center, The Persian Gulf Biomedical Research Institute, Bushehr University of Medical Sciences, Bushehr, Iran

${ }^{d}$ Department of Biochemistry, Faculty of Medicine, Bushehr University of Medical Sciences, Bushehr, Iran
\end{abstract}

Received 9 January 2021; Accepted 26 June 2021

Available online 1 September 2021

\section{KEYWORDS \\ allergic diseases; \\ GA2LEN; \\ COVID-19; \\ SARS-CoV-2; \\ underlying diseases}

\begin{abstract}
Introduction: Allergic diseases could play a role of a predisposing factor for coronavirus disease 2019 (COVID-19). The aim of this study was to investigate allergic comorbidity and its association in COVID-19 patients.

Methods: Demographic data, clinical manifestations, laboratory reports, and radiologic findings, together with underlying comorbidity of patients, were studies. Allergic diseases were identified by using the standard GA ${ }^{2}$ LEN questionnaire. The severity of COVID-19 was assessed by a visual analog scale (VAS) and an intensive care unit (ICU) report.

Results: Out of 400 COVID-19 patients admitted in the hospital, 158 (39.5\%) presented with different allergic diseases, and a reverse association was observed between having allergic comorbidity and severity of COVID-19 infection $(P=0.005$, relative risk $=0.96$; $95 \%$ Confidence Interval (95\% Cl): $0.77-1.19)$. The respective frequency of asthma, allergic rhinitis (AR), chronic rhinosinusitis (CRS), atopic dermatitis, chronic urticaria, and food or drug allergy was $7.3 \%$, $16 \%, 1.8 \%, 5 \%, 10 \%$ and $13.3 \%$. Significantly, only AR was reversely associated with the severity of COVID-19 ( $P=0.02$, relative risk $=0.45 ; 95 \% \mathrm{Cl}$ : 0.77-1.19). Additionally, $43 \%$ of the patients presented hypoxemia, and $93.5 \%$ had chest CT scan involvement. Interestingly, patients with allergic diseases had significantly lower hypoxemia and chest $\mathrm{CT}$ involvement as compared with non-allergic patients $(P=0.002$ and 0.003 , respectively).
\end{abstract}

*Corresponding author: Shokrollah Farrokhi, MD, PhD, Department of Immunology and Allergy, The Persian Gulf Tropical Medicine Research Center, Bushehr University of Medical Sciences, Emam Khomeini St, PO Box: 75166888 76, Bushehr, Iran. Email address: Farrokhi_sh@yahoo.com 
Conclusion: The results of this study established that allergic diseases were not determined to be a predisposing factor for the severe acute respiratory syndrome (SARS) due to coronavirus 2 (SARS-CoV-2) infection. Significantly, AR patients developed mild clinical manifestations of COVID-19 and admitted to ICU as compared to non-AR patients.

(C) 2021 Codon Publications. Published by Codon Publications.

\section{Introduction}

Coronavirus disease 2019 (COVID-19), caused by severe acute respiratory syndrome coronavirus 2 (SARS-CoV-2), has rapidly spread globally, with sharp increase in Iran and some other countries. The disease causes severe pneumonia and other complications, including death in severely affected patients. ${ }^{1,2}$ Clinical manifestations of the COVID-19 infection reported so far include headache, fever, cough, shortness of breath, and breathing difficulties as well as taste and smell dysfunction. Generally, nasal symptoms and sore throat could be the result of viral airway infection, but in some severe cases, the infection could lead to pneumonia, SARS, renal failure, and death. ${ }^{3-6}$

It has been reported that COVID-19 might result in severe conditions because of different comorbidities, including hypertension (HTN), chronic obstructive pulmonary disease (COPD), diabetes mellitus (DM), cardiovascular disease, and obesity. ${ }^{7}$ A study conducted in China on the clinical characteristics of 1099 COVID-19 patients has demonstrated that $15.7 \%$ of patients had severe pneumonia. $^{8}$

Allergic respiratory diseases, especially allergic rhinitis (AR), chronic rhinosinusitis (CRS), and asthma (AS), affect a large global population, and because of chronic inflammatory characteristics of these diseases, they may influence susceptibility to the SARS-CoV-2 infection and could be a cause of severe COVID-19.,10 Presently, only few data are available to confirm a specific increased risk for COVID-19 in patients with underlying allergic diseases. However, another study from China has recently reported that these diseases could not be considered as risk factors for severe COVID-19 disease. ${ }^{5}$ Moreover, some data have depicted that the prevalence of asthma in the COVID-19 patients in China was less than $1 \%{ }^{11}$ whereas in the United States, prevalence of asthma was reported as 7-17\%.12,13 Therefore, there may exist a risk for exacerbation of allergic diseases, especially asthma, triggered by SARS-CoV-2 as a respiratory viral infection. ${ }^{14}$

Owing to the epidemic status of COVID-19 in Iran, many studies have reported the clinical features of the disease; however, as far as the present study is concerned, there has been no study that assessed the frequency of allergic diseases and their association with COVID-19. Therefore, this study investigated the clinical and laboratory characteristics of COVID-19 patients admitted in wards, intensive care unit (ICU), and out patients department (OPD), associating severe and nonsevere conditions based on ICU admission and visual analog scale (VAS). Moreover, the frequency of allergic and other underlying diseases as associated comorbidity was determined in patients having COVID-19. Finally, association between COVID-19 and allergic diseases as a risk factor was examined.

\section{Materials and methods}

\section{Data collection of the COVID-19 patients}

This case series study was conducted in the general hospital affiliated to the Bushehr University of Medical Sciences (BPUMS), Iran. All the 400 patients tested positive for SARSCoV-2 infection (identified by using Reverse TranscriptasePolymerase Chain Reaction [RT-PCR] test) participated in this study. The patients were split in three groups: 68 patients were admitted in ICU, 270 were admitted in wards, and 62 were treated as OPD patients. Demographic data and clinical manifestations of the COVID-19 patients, including fever, general condition, respiratory, and gastrointestinal (GI) indications were recorded by trained medical staff in a questionnaire. The severity of COVID-19 was assessed at the time of admission using VAS. Patients admitted in the ICU were considered as severe cases. Laboratory findings and computed tomographic (CT) scan of the chest of each patient were obtained and evaluated from the electronic medical record system of the hospital. In addition, we assessed other underlying diseases, such as diabetes mellitus, hypertension, cardiovascular, brain, liver, thyroid, and kidney disorders of the patients by self-reporting. This study was approved by the Ethics Committee of the Bushehr University of Medical Sciences, Bushehr, Iran (ethical approval code: IR.BPUMS.REC.1399.083).

\section{Identification of allergic diseases in COVID-19 patients}

For identification and epidemiological investigation of allergic diseases in the COVID-19 patients, we used the standard questionnaire of the Global Allergy and Asthma European Network $\left(G A^{2} L E N\right) .{ }^{15}$ For this questionnaire, details of all allergic disorders, such as AR, allergic rhinoconjunctivitis (ARC), chronic rhinosinusitis, asthma, chronic urticaria (CU), atopic dermatitis (AD), and food or drug allergy, were obtained as self-reported by the patients based on the questions about the diseases as stated in the GA2LEN questionnaire. Furthermore, other physicians also diagnosed the stated diseases, including COPD.

\section{Statistical analysis}

Descriptive statistics such as mean value and standard deviation (SD) of laboratory findings and the frequency distribution of age groups, gender, smoking status, allergic diseases, underlying diseases, and COPD in the COVID-19 patients were determined. Association between 
demographic characteristics and clinical data of the patients was evaluated using Chi-square test. Moreover, Chi-square test was also used for assessing the correlation between allergic diseases, COPD, and other underlying comorbid diseases and the COVID-19 manifestations and its severity (admission in ICU and VAS). Differences in laboratory findings were compared using two independent $t$-tests, and $\mathrm{P}<0.05$ was considered statistically significant. All statistical analyses were performed using IBM SPSS Statistics for Windows, version 22 (IBM Corp., Armonk, NY, USA).

\section{Results}

In this study, 400 COVID-19 patients (51.2\% males and $48.8 \%$ females) were enrolled. The mean (SD) age of all the patients was 49.2 with a range of 17-92 years. Of the 400 patients, 62 (15.5\%) were OPD patients, and 270 (67.5\%) and 68 (17\%) were admitted in wards and ICU, respectively. Demographic and clinical data of the patients are provided in Table 1.

\section{Clinical manifestations of COVID-19 patients}

The most common clinical manifestations of the patients were chest tightness/dyspnea (78.5\%), fatigue (77.3\%), cough $(69 \%)$, and fever (64\%). Severity of the patient's clinical manifestations based on self-reported VAS was mild (41\%), moderate $(47 \%)$, and severe $(12 \%)$. There was an association between having fever $(P=0.005)$, chest tightness/dyspnea $(P<0.001)$, severe headache $(P=0.01)$, anosmia/hyposmia $(P<0.001)$, and $G$ manifestations $(P<0.001)$ and treatment of OPD patients. On the other hand, there was an association between having cough $(P=0.01)$, chest tightness/dyspnea $(P=0.01)$, anosmia/hyposmia $(P=0.01)$, and diarrhea $(\mathrm{P}=0.01)$ and admission in wards (Table 2$)$.

Table 1 Demographic and clinical data of COVID-19 patients.

\begin{tabular}{|c|c|c|c|c|}
\hline Variable & $\begin{array}{c}\text { Total patients, } \\
\text { N (\%) }\end{array}$ & $\begin{array}{l}\text { ICU admissions, } \\
\text { N (\%) }\end{array}$ & $\begin{array}{l}\text { Non-ICU admissions (Outpatients } \\
\text { and wards admission) N (\%) }\end{array}$ & P-value \\
\hline Males & $205(51.2)$ & $40(10)$ & $165(41.2)$ & 0.1 \\
\hline Females & $195(48.8)$ & $28(7)$ & $167(58.8)$ & \\
\hline \multicolumn{5}{|l|}{ Age group (years) } \\
\hline$<30$ & $45(11.2)$ & $4(1)$ & $41(10.2)$ & 0.00 \\
\hline $30-39$ & $83(20.8)$ & $10(2.5)$ & $73(18.2)$ & \\
\hline $40-49$ & $88(22)$ & $9(2.2)$ & $79(19.7)$ & \\
\hline $50-59$ & $65(16.3)$ & $9(2.2)$ & $56(14)$ & \\
\hline$\geq 60$ & $119(29.7)$ & $35(8.7)$ & $84(21)$ & \\
\hline Fever & $256(64)$ & $44(17.2)$ & $212(82.8)$ & 0.5 \\
\hline Cough & $276(69)$ & 47 (17) & $229(83)$ & 0.5 \\
\hline Fatigue & 309 (77.3) & $46(14.9)$ & $263(83.5)$ & 0.03 \\
\hline Chest tightness/dyspnea & $314(78.5)$ & $61(19.4)$ & $253(80.6)$ & 0.008 \\
\hline Severe headache & $160(40)$ & $18(11.3)$ & $142(88.8)$ & 0.008 \\
\hline Anosmia/hyposmia & $51(12.8)$ & $3(5.9)$ & $48(94.1)$ & 0.001 \\
\hline Nausea and vomiting & $126(31.5)$ & $19(15.1)$ & $107(84.9)$ & 0.2 \\
\hline Diarrhea & $88(22)$ & $10(11.4)$ & $78(87.6)$ & 0.07 \\
\hline Abdominal pain/dyspepsia & $82(20.5)$ & $8(9.8)$ & $84(90.2)$ & 0.03 \\
\hline Anorexia & $225(56.3)$ & $29(12.9)$ & $196(87.1)$ & 0.01 \\
\hline Oral aphthous & $20(5)$ & $3(15)$ & $17(85)$ & 0.5 \\
\hline Smoking & $109(27.3)$ & $22(5.5)$ & $87(21.7)$ & 0.05 \\
\hline \multicolumn{5}{|l|}{ Allergic diseases (self-reported) } \\
\hline Allergic rhinitis & $64(16)$ & $5(7.8)$ & $59(92.2)$ & 0.02 \\
\hline Allergic rhinoconjunctivitis & $52(13)$ & $5(9.6)$ & $47(90.4)$ & 0.08 \\
\hline Chronic rhinosinusitis & $7(1.8)$ & 0 & $7(100)$ & 0.2 \\
\hline Asthma & $29(7.3)$ & $2(6.9)$ & $27(93.1)$ & 0.09 \\
\hline Atopic dermatitis & $20(5)$ & $1(5)$ & $19(95)$ & 0.1 \\
\hline Chronic urticaria & $40(10)$ & $3(7.5)$ & 37 (92.5) & 0.06 \\
\hline Total & $158(39.5)$ & $16(10.8)$ & $142(89.2)$ & 0.005 \\
\hline \multicolumn{5}{|l|}{ Comorbid diseases (self-reported) } \\
\hline Hypertension & $99(24.8)$ & $30(30.3)$ & $69(69.7)$ & 0.00 \\
\hline Diabetes mellitus & $78(19.5)$ & $17(21.8)$ & $61(78.2)$ & 0.1 \\
\hline Thyroid disorders & $26(6.5)$ & $6(21.3)$ & $20(76.9)$ & 0.2 \\
\hline Fatty liver & $108(27)$ & $23(21.3)$ & $85(78.7)$ & 0.1 \\
\hline Cardiovascular disorders & $65(16.3)$ & $22(33.8)$ & $43(66.2)$ & 0.00 \\
\hline Brain diseases & $25(6.3)$ & $11(44)$ & $14(56)$ & 0.001 \\
\hline Kidney diseases & $32(8)$ & $9(28.1)$ & $23(71.9)$ & 0.07 \\
\hline Total & $260(65)$ & $53(20.4)$ & $207(79.6)$ & 0.009 \\
\hline
\end{tabular}


Table 2 Clinical manifestations and paraclinical data of COVID-19 patients with or without allergic comorbidity.

\begin{tabular}{|c|c|c|c|}
\hline Variable & $\begin{array}{c}\text { Patients with allergic } \\
\text { comorbidity, N (\%) }\end{array}$ & $\begin{array}{l}\text { Patients without allergic } \\
\text { comorbidity, } \mathrm{N}(\%)\end{array}$ & P-value \\
\hline Gender & & & 0.00 \\
\hline Male & $63(30.7)$ & $142(69.3)$ & \\
\hline Female & $95(48.7)$ & $100(51.3)$ & \\
\hline Age group (years) & & & 0.02 \\
\hline$<30$ & $23(51.1)$ & $22(48.9)$ & \\
\hline $30-39$ & $42(50.6)$ & $41(49.4)$ & \\
\hline $40-49$ & $35(39.8)$ & $53(60.2)$ & \\
\hline $50-59$ & $22(33.8)$ & $43(66.2)$ & \\
\hline$\geq 60$ & $36(30.5)$ & $82(69.5)$ & \\
\hline Fever & $104(65.8)$ & $152(62.8)$ & 0.3 \\
\hline Cough & $112(70.9)$ & $164(67.8)$ & 0.2 \\
\hline Fatigue & $126(79.7)$ & $153(75.6)$ & 0.2 \\
\hline Chest tightness/dyspnea & $126(79.7)$ & $188(77.7)$ & 0.3 \\
\hline Severe headache & $75(47.5)$ & $85(35.1)$ & 0.009 \\
\hline Anosmia/hyposmia & $32(20.3)$ & $19(7.9)$ & 0.00 \\
\hline Nausea and vomiting & $70(44.3)$ & $56(23.1)$ & 0.00 \\
\hline Diarrhea & $37(23.4)$ & $51(21.1)$ & 0.3 \\
\hline Abdominal pain/dyspepsia & $36(22.8)$ & 46 (19) & 0.2 \\
\hline Anorexia & $94(59.5)$ & $131(54.1)$ & 0.1 \\
\hline Oral aphthous & $11(7)$ & $9(3.7)$ & 0.1 \\
\hline Severity of symptoms & & & 0.3 \\
\hline \multicolumn{4}{|l|}{ (VAS; self-reported) } \\
\hline Mild & $70(44.3)$ & $94(38.8)$ & \\
\hline Moderate & $73(46.2)$ & $115(47.5)$ & \\
\hline Severe & $15(9.5)$ & $33(13.6)$ & \\
\hline WBC (total number) & $6900 \pm 313$ & $7200 \pm 283$ & 0.4 \\
\hline Neutrophil (\%) & $73.3 \pm 12$ & $74.4 \pm 12$ & 0.3 \\
\hline Lymphocyte (\%) & $19.5 \pm 9.8$ & $18.4 \pm 10.3$ & 0.3 \\
\hline Platelets (n) & $215000 \pm 8000$ & $212000 \pm 5000$ & 0.8 \\
\hline $\operatorname{ESR}(\mathrm{mm} / \mathrm{h})$ & $45.1 \pm 2.1$ & $46.6 \pm 1.7$ & 0.5 \\
\hline CRP (mg/L) & $61 \pm 3.7$ & $66.1 \pm 2.9$ & 0.2 \\
\hline SGOT (IU/L) & $42.7 \pm 2.7$ & $44.8 \pm 2.3$ & 0.5 \\
\hline SGPT (IU/L) & $45.5 \pm 3$ & $46.2 \pm 3.1$ & 0.8 \\
\hline AP (IU/L) & $202.3 \pm 11.3$ & $198.2 \pm 5.2$ & 0.7 \\
\hline Hypoxemia $\left(\mathrm{SpO}_{2}<93 \%\right)$ & $54(34.2)$ & $118(49)$ & 0.002 \\
\hline $\mathrm{CT}$, chest involvement & & & 0.003 \\
\hline No & $18(11.5)$ & $8(3.3)$ & \\
\hline Mild & $24(15.3)$ & $39(16.3)$ & \\
\hline Moderate & $68(43.3)$ & $92(38.8)$ & \\
\hline Severe & 47 (29.9) & $102(42.3)$ & \\
\hline
\end{tabular}

WBC: white blood cells; ESR: erythrocyte sedimentation rate; CRP: C-reactive protein; SGOT: serum glutamic-oxaloacetic transaminase; SGPT: serum glutamic-pyruvic transaminase; AP: alkaline phosphatase.

\section{Allergic comorbidity in COVID-19 patients}

The total frequency of allergic comorbidity in COVID-19 patients was 158 (39.5\%), and it was reversely associated with the severity of COVID-19 as required for admission in ICU $(\mathrm{P}=0.005$, relative risk $=0.96 ; 95 \% \mathrm{Cl}$ : 0.25-0.81). Moreover, a relationship was established between having allergic comorbidity and OPD treatment for COVID-19 $(\mathrm{P}=0.02$, relative risk $=1.7 ; 95 \% \mathrm{Cl}: 1.03-2.8)$. Frequency of allergic diseases in COVID-19 patients is shown in Figure 1. The number of patients having asthma was 29 (7.3\%). However, no relationship was established between having asthma and admission in wards $(P=0.4)$ or OPD treatment $(P=0.1)$. Importantly, only two patients $(0.5 \%)$ with asthma had acute clinical manifestations of COVID-19 and admitted in the ICU. In addition, of the total number of patients with COVID-19, 64 (16\%) had AR; of these 22 (5.5\%) were treated as outpatients and 23 (5.7\%) were admitted in wards (self-reported). Furthermore, a relationship was observed between having $A R$ and OPD treatment $(P=0.002)$; however, no relationship was established between having $A R$ and admission in wards $(P=0.1)$. We had only two patients with CRS and nasal polyp (CRSwNP). The frequency of having food or drug allergy and COPD was $13.3 \%$ and $6.8 \%$, 


\section{Allergy Comorbidity}

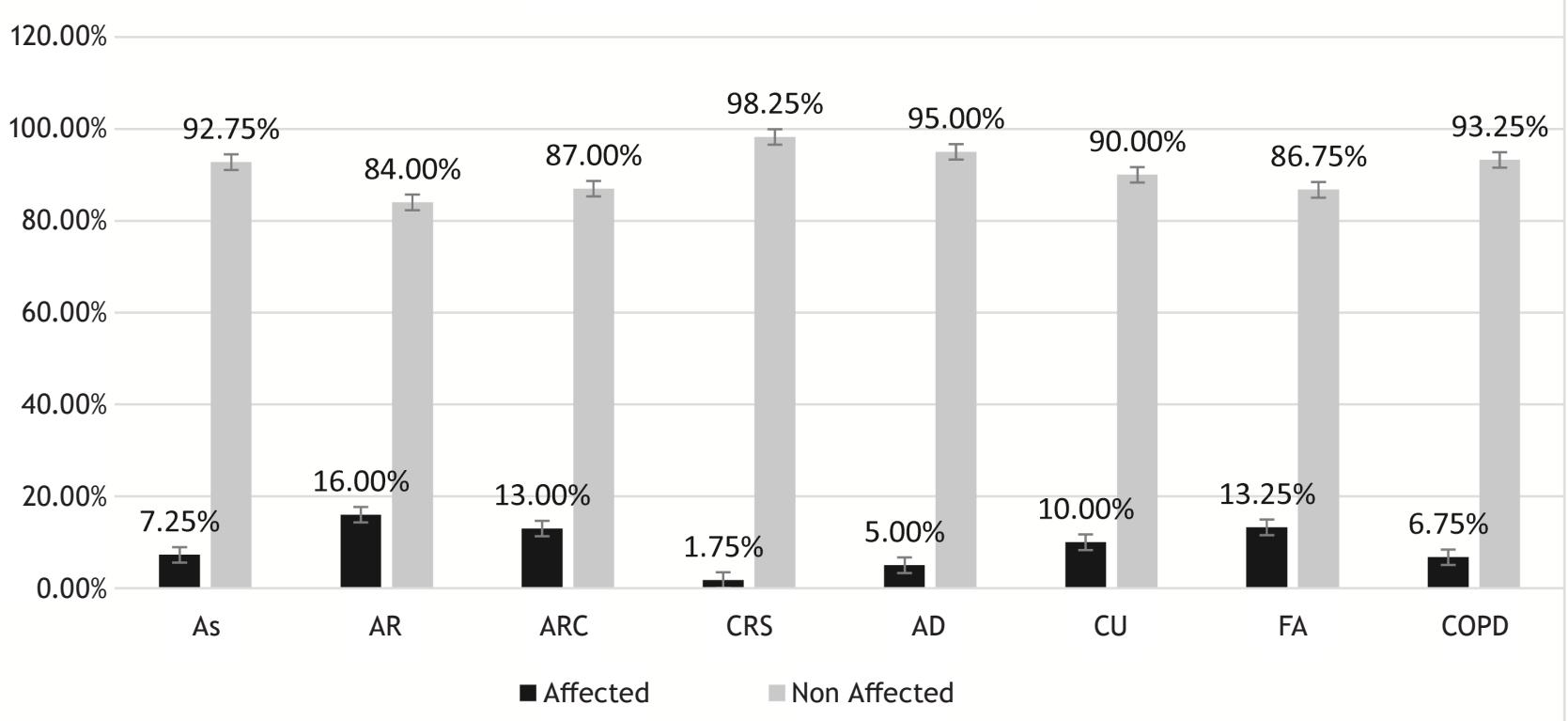

Figure 1. The frequency of allergic diseases in COVID-19 patients. AR: Allergic rhinitis; ARC: Allergic rhinoconjunctivitis; CRS: Chronic rhinosinusitis; AS: Asthma; CU: Chronic urticaria; AD: Atopic dermatitis; FA: Food allergy; COPD: Chronic obstructive pulmonary disease

respectively. It is important to note that no relationship was demonstrated between having comorbidity of atopic dermatitis $(P=0.02)$, chronic urticaria $(P=0.02)$, or COPD $(\mathrm{P}=0.002)$ and $\mathrm{OPD}$ treatment.

Moreover, in the past 12 months, 3.5\% of the patients had reported wheezing or whistling sound in the chest, $2.5 \%$ had shortness of breath, $2.5 \%$ had an attack of cough, and $2.5 \%$ had sputum in the chest. Further, a relationship was demonstrated between having a cough attack and both OPD treatment and patients admitted in wards $(P=0.04$ and 0.01 , respectively). Only $1 \%$ of the patients reported reduced feeling or loss of smell in the past 12 months.

It was observed that $54(34.2 \%)$ of the total patients with allergic comorbidity had hypoxemia. A significant difference was observed between having allergic comorbidity and lower presence of hypoxemia during COVID-19 $(\mathrm{P}=0.002$, relative risk $=0.54 ; 95 \% \mathrm{Cl}: 0.35-0.81)$. In addition, $94(23.5 \%)$ of the total patients had both allergic and other underlying diseases. In addition, no association was observed between having both allergy and some above-mentioned underlying diseases and severity of COVID-19 ( $P>0.05)$. The frequency of underlying diseases in COVID-19 patients is shown in Table 1. Finally, 40 (10\%) of the total patients were smokers and have allergic diseases simultaneously. However, this condition was not associated with the severity of COVID-19 ( $P>0.05)$.

\section{Discussion}

To the best of our knowledge, this is the first study conducted in Iran considering patients with COVID-19 and its association with the comorbidity of allergic diseases. In the present study, 400 patients, including ward/ICU admissions and OPD patients, infected with SARS-COV-2 were examined for allergic diseases.

The total frequency of allergic comorbidity among COVID-19 patients was $39.5 \%$, and it was reversely associated with the severity of COVID-19 manifestations in such a manner that these patients had significantly lower admissions in the ICU than the patients with no signs of allergy. However, there was a significant association between having allergic comorbidity and OPD treatment of COVID-19. Several studies having assessed the association between respiratory viral infection, such as respiratory syncytial virus (RSV) and exacerbation of respiratory allergic diseases, reported that viral infections of the respiratory tract are associated with exacerbation of diseases. ${ }^{16,17}$ It was confirmed that angiotensin-converting enzyme 2 (ACE2) and transmembrane protease serine 2 (TMPRSS2), which are expressed in airway epithelial cells, were identified as the main receptors of SARS-CoV-2. Moreover, other studies have reported that patients with allergic respiratory diseases have downregulated ACE2 expression in nasal and bronchial epithelial cells. Further, another study has established that use of inhaled corticosteroids (ICS) was associated with the downregulation of both ACE2 and TMPRSS2 receptors. ${ }^{18-20}$ Taken together, despite having the presence of allergic diseases in a large proportion of general population; these were not determined to be a predisposing factor for the SARS-CoV-2 infection.

In addition, our study established that asthma was present in $7.3 \%$ of the patients, including admitted and OPD patients. According to our previous study, the prevalence of asthma in the region was $10 \%$ in general population. ${ }^{21}$ However, in the present study, we noticed that frequency 
of asthma among the admitted COVID-19 patients was $5.2 \%$. Therefore, our data revealed that asthmatic patients are less likely to develop COVID-19 as compared to general population. However, a US study conducted on 1526 patients identified with COVID-19 has reported that $14.4 \%$ of the patients had asthma. Other recent studies from the United States have demonstrated that the prevalence of asthma in the admitted COVID-19 patients was $7-17 \% .{ }^{7,13,14}$ Contrary to the present study, a study conducted in China did not identify any asthmatic case among 140 COVID-19 patients. ${ }^{5}$ Thus, the controversy over prevalence of asthma could be related to geographic variations or different methods of assessment and epidemiologically identified asthma. In addition, our findings were in line with a US study which evidenced that there was no association between asthma comorbidity and the severity of COVID-19 as required for ICU care. ${ }^{14}$

The frequency of other allergic diseases such as $A R$, chronic rhinosinusitis, atopic dermatitis, chronic urticaria, and food or drug allergy in COVID-19 patients was $16 \%, 1.8 \%, 5 \%, 10 \%$ and $13.3 \%$, respectively. In addition, the present data depicted that the severity of COVID-19 required for admission in ICU was significantly lower in AR patients, which is not in agreement with the outcome of Chinese study pointing no allergic disease. ${ }^{5}$

We also assessed comorbidities of both allergic and other underlying diseases such as diabetes mellitus, hypertension, cardiovascular, brain, liver, thyroid, and kidney disorders in COVID-19 patients. Interestingly, our data demonstrated that $23.5 \%$ of COVID-19 patients had allergic and other underlying diseases as comorbidities. Furthermore, the above-mentioned comorbidities were not associated with the severity of COVID-19. However, recent studies have demonstrated that some underlying diseases such as diabetes mellitus and cardiovascular diseases are the risk factors for COVID-19.,22 The result of our study suggested that comorbidity of allergic diseases and the use of corticosteroids may be downregulating ACE2 and TMPRSS2 receptors, leading to a decrease in the risk of SARS-CoV-2 infection in patients with underlying diseases. ${ }^{19}$ In addition, the present study has established that although $10 \%$ of the patients had allergic diseases and smoking habit simultaneously, they depicted no association with the severity of COVID-19. Moreover, COPD as an underlying disease witnessed in $6.8 \%$ of the patients was not associated with the severity of COVID-19. In the study conducted in China, only two $(1.4 \%)$ of the 140 patients were reported with COPD, which confirmed that COPD played a minor role in the exacerbation of COVID-19.5

Noticeably, the results of the present study indicated that $93.5 \%$ of COVID-19 patients had involvement of chest CT scan, and $43 \%$ of them presented hypoxemia. Zhang et al. have reported the presence of bilateral ground-glass and patchy opacity in CT scan or X-ray in 89.6\% of COVID-19 patients. ${ }^{5}$ Interestingly, our data indicated that patients with allergic diseases had significantly lower hypoxemia and involvement of chest CT.

The data from the present study was in line with other studies expressing that males were more affected with COVID-19 compared to females among admitted and OPD patients, and the number of males with COVID-19 admitted in ICU was higher than females $(10 \%$ vs. $7 \%$, respectively). In addition, males were significantly less likely to present allergic diseases than females (30.7\% vs. $48.7 \%$, respectively). Further, the data established that most of the patients frequently referred with COVID-19 were aged 60 years and above, and more admissions in ICU were made from this age group than other groups. In addition, the highest frequency of allergic diseases was determined in the age group of 30-35 years. 4,5,23 Therefore, we conclude that allergic diseases which are more frequent in younger age groups could be due to factors that alleviate the severity of COVID-19 symptoms. However, further investigations are required to determine why these conditions lead to better COVID-19-related outcomes.

The most common symptoms reported in the patients of our study were chest tightness/dyspnea, fatigue, cough, and fever. On the other hand, the study from China has reported that fever, cough, and fatigue were the prior symptoms determined in COVID-19 patients. ${ }^{5}$ Therefore, the frequency of COVID-19 symptoms may vary with diversity in populations.

\section{Limitations}

There were several limitations to our study. The first was that since some of the data were obtained from the electronic medical record system of the hospital, we were limited to performing specific tests, such as immunoglobulin $\mathrm{E}$ (IgE), for more accurate diagnosis of allergic diseases. The second limitation was that critically ill patients admitted in ICU and wards were less cooperative in answering the related questions.

\section{Conclusion}

The present study established that allergic diseases and asthma, present in a large proportion of general population, were not predisposing factors for SARS-CoV-2 infection. Interestingly, the patients with AR developed mild symptoms of COVID-19, and significantly fewer were admitted in ICU as compared to non-AR patients. Moreover, allergic conditions as underlying diseases in COVID-19 patients were not associated with the severity of the disease or the number of admissions in ICU. Finally, the data revealed that more males were affected by COVID-19 and admitted in ICU compared to females.

\section{Acknowledgements}

This study was funded by Bushehr University of Medical Sciences (BPUMS), Bushehr, Iran.

\section{Conflict of interest}

There were no conflicts of interest in this study. 


\section{References}

1. Cai Q, Huang D, Ou P, Yu H, Zhu Z, Xia Z, et al. COVID-19 in a designated infectious diseases hospital outside Hubei Province, China. Allergy. 2020, Jul;75(7):1742-52. https://doi. org/10.1111/all.14309

2. Nikpouraghdam M, Farahani AJ, Alishiri G, Heydari S, Ebrahimnia $M$, Samadinia $H$, et al. Epidemiological characteristics of coronavirus disease 2019 (COVID-19) patients in Iran: A single center study. J Clin Virol 2020, Jun;127:104378. https://doi.org/10.1016/j.jcv.2020.104378

3. Chen Y, Liu Q, Guo D. Emerging coronaviruses: Genome structure, replication, and pathogenesis. J Med Virol. 2020, Apr;92(4):418-23. https://doi.org/10.1002/jmv.25681

4. Huang C, Wang Y, Li X, Ren L, Zhao J, Hu Y, et al. Clinical features of patients infected with 2019 novel coronavirus in Wuhan, China. Lancet. 2020, Jan;395(10223):497-506. https:// doi.org/10.1016/S0140-6736(20)30183-5

5. Zhang J-j, Dong X, Cao Y-y, Yuan Y-d, Yang Y-b, Yan Y-q, et al. Clinical characteristics of 140 patients infected with SARS-CoV-2 in Wuhan, China. Allergy. 2020, Jul; 75(7):1730-41. https://doi.org/10.1111/all.14238

6. Zhou F, Yu T, Du R, Fan G, Liu Y, Liu Z, et al. Clinical course and risk factors for mortality of adult inpatients with COVID-19 in Wuhan, China: A retrospective cohort study. Lancet. 2020, Mar;395(10229):1011-88, e54-e61. https://doi.org/10.1016/ S0140-6736(20)30566-3

7. Richardson S, Hirsch JS, Narasimhan M, Crawford JM, McGinn T, Davidson KW, et al. Presenting characteristics, comorbidities, and outcomes among 5700 patients hospitalized with COVID-19 in the New York City area. JAMA. 2020;323(20):2052-59. https://doi.org/10.1001/jama.2020.6775

8. Guan W-j, Ni Z-y, Hu Y, Liang W-h, Ou C-q, He J-x, et al. Clinical characteristics of coronavirus disease 2019 in China. New Engl J Med (NEJM). 2020;382(18):1708-20. https://doi. org/10.1056/NEJMoa2002032

9. Kim S, Jung CG, Lee JY, Kim G, Choi SW, Jin HJ, et al. Characterization of asthma and risk factors for delayed SARS-CoV-2 clearance in adult COVID-19 inpatients in Daegu. Allergy. 2021, Mar;76(3):918-21. https://doi.org/10.1111/all.14609

10. Riggioni C, Comberiati P, Giovannini $M$, Agache I, Akdis $M$, Alves-Correia $M$, et al. A compendium answering 150 questions on COVID-19 and SARS-CoV-2. Allergy. 2020, Oct;75(10):250341. https://doi.org/10.1111/all.14449

11. Chen N, Zhou M, Dong X, Qu J, Gong F, Han Y, et al. Epidemiological and clinical characteristics of 99 cases of 2019 novel coronavirus pneumonia in Wuhan, China: A descriptive study. Lancet. 2020, Feb;395(10223):507-13. https://doi. org/10.1016/S0140-6736(20)30211-7

12. Bhatraju PK, Ghassemieh BJ, Nichols M, Kim R, Jerome KR, Nalla AK, et al. Covid-19 in critically ill patients in the Seattle
region-Case series. New Engl J Med (NEJM). 2020;382(21):201222. https://doi.org/10.1056/NEJMoa2004500

13. Myers LC, Parodi SM, Escobar GJ, Liu VX. Characteristics of hospitalized adults with COVID-19 in an integrated health care system in California. JAMA. 2020, Jun;329(21):2195-98. https://doi.org/10.1001/jama.2020.7202

14. Chhiba KD, Patel GB, Vu THT, Chen MM, Guo A, Kudlaty E, et al. Prevalence and characterization of asthma in hospitalized and nonhospitalized patients with COVID-19. J Allergy Clin Immunol. 2020;146(2):307-14.e4. https://doi.org/10.1016/j. jaci.2020.06.010

15. Bousquet J, Burney P, Zuberbier T, Cauwenberge PV, Akdis C, Bindslev-Jensen C, et al. GA2LEN (Global Allergy and Asthma European Network) addresses the allergy and asthma "epidemic". Allergy. 2009;64(7):969-77. https://doi. org/10.1111/j.1398-9995.2009.02059.x

16. Greenberg SB, editor. Respiratory viral infections: Update on human rhinovirus and coronavirus infections. Seminars in respiratory and critical care medicine. New York, NY: Thieme; 2016.

17. Kurai D, Saraya T, Ishii H, Takizawa H. Virus-induced exacerbations in asthma and COPD. Front Microbiol. 2013;4:293. https://doi.org/10.3389/fmicb.2013.00293

18. Hoffmann $M$, Kleine-Weber $H$, Schroeder $S$, Krüger $N$, Herrler T, Erichsen S, et al. SARS-CoV-2 cell entry depends on ACE2 and TMPRSS2 and is blocked by a clinically proven protease inhibitor. Cell. 2020;118(2):271-80. https://doi. org/10.1016/j.cell.2020.02.052

19. Jackson DJ, Busse WW, Bacharier LB, Kattan M, O’Connor GT, Wood RA, et al. Association of respiratory allergy, asthma and expression of the SARS-CoV-2 receptor, ACE2. J Allergy Clin Immunol. 2020, Jul;146(1):203-06.e3. https://doi. org/10.1016/j.jaci.2020.04.009

20. Peters MC, Sajuthi S, Deford P, Christenson S, Rios CL, Montgomery MT, et al. COVID-19-related genes in sputum cells in asthma: Relationship to demographic features and corticosteroids. Am J Respir Crit Care Med. 2020, Jul;202(1): 83-90. https://doi.org/10.1164/rccm.202003-08210C

21. Ostovar A, Fokkens WJ, Pordel S, Movahed A, Ghasemi K, Marzban $M$, et al. The prevalence of asthma in adult population of southwestern Iran and its association with chronic rhinosinusitis: A GA 2 LEN study. Clin Transl Allergy. 2019;9(1):43. https://doi.org/10.1186/s13601-019-0283-6

22. Garg S. Hospitalization rates and characteristics of patients hospitalized with laboratory-confirmed coronavirus disease 2019-COVID-NET, 14 states, March 1-30, 2020. MMWR Morb Mortal Wkly Rep (MMWR). 2020 Apr;69(15):458-64. http://dx. doi.org/10.15585/mmwr.mm6915e3

23. Wang D, Hu B, Hu C, Zhu F, Liu X, Zhang J, et al. Clinical characteristics of 138 hospitalized patients with 2019 novel coronavirus-infected pneumonia in Wuhan, China. JAMA. 2020, Feb;323(11):1061-9. https://doi.org/10.1001/jama.2020.1585 